\title{
Editing a journal in an era of publishing change
}

\author{
EUGENE PAYKEL
}

Editor, Psychological Medicine

I have been an editor for more than 23 years. Viewed in retrospect my earlier personal history had ominous markers for the future. These included editorial work for school and medical school magazines, and, as a psychiatric researcher, enjoyment of the writing of papers more than some of my colleagues, albeit with the usual features of painful struggle. Later I edited some psychiatric books (and found that hard labour). Then George Winokur and I were invited to start the new Journal of Affective Disorders, with its first issue at the beginning of 1979 . Fifteen years later I accepted a similar invitation from Cambridge University Press, the large academic press of what was by then my home University, to succeed Michael Shepherd, a most distinguished editor, in the Editorship of Psychological Medicine.

Editors are not always the most popular of people. All researchers have, as authors of papers, had bruising experiences when editors decline to publish our cherished works. We have marvelled at the lack of perception and judgement which can lead people to take such arbitrary decisions. Editors as authors have had the same experiences when sitting on the author's side of the desk.

Actually, when one finds oneself doing it, the work is hard. It has been compared, in its less rewarding aspects, to delivering other people's beautiful babies. Psychological Medicine is a major journal, with a high number of submitted papers, averaging about 50 a month and rising. Considering them with the proper attention is rather like walking on a treadmill. Look away and ignore the task for a short period, the backlog builds up, and some kind of untoward consequence looms. Most of us are always trying to keep our own research active at the

Address for correspondence: Professor E. Paykel, University of Cambridge, Department of Psychiatry, Douglas House, 18E Trumpington Road, Cambridge CB2 2AH (UK).

Declaration of Interest: the declaration is indicated in Psychological Medicine. same time. At least the simultaneous experience of undertaking research can help to keep a sense of balance regarding the difficulties of bringing to successful and published fruition a good research study. No study can be perfect and critics of individual papers from the sidelines are at risk of lofty judgements which are divorced from the reality of delivering valid findings which can advance a field.

On the other hand there are also rewards for the editor. There is the privilege of reading new and exciting papers before they are known to the world, and of learning how to judge over a wide area from the assessments of experts in each specific field. There are the pleasures of acquaintance with the wide network of authors and assessors with whom one corresponds and who from time to time one meets. Sometimes there is their thanks. There is a definite sense of achievement if you manage to do the job well and successfully. No one is forced against their will to become an editor.

At Psychological Medicine most published papers undergo editorial consideration at three separate stages: an initial reading with some exercise of judgement, when assessors are selected; a second reading when assessors' reports have been received and a decision needs to be taken; and for most ultimately published papers, further consideration after a revision in the light of assessors' comments. I am able to share this work with the American Editor and Associate Editors. There is always pressure to expedite matters. Delay in decisions and in publication should not be inflicted on authors and we are proud of the rapid turnaround we achieve. The Editorial Board are always available for advice regarding papers and assessors, and major policy decisions. Assessors also work hard and their work is potentially as ungratefully received as the editor's may be. Good experts with high reputations are much in demand, and have to ration their time. Journals are most grateful for those who provide opinions.

A well organised editorial office is an essential. Lynet Smith and I have worked together for some years. She is 
an expert on tasks as diverse as setting up, managing and modifying a complex database, locating assessors of known name but sometimes uncertain address worldwide, tracking the progress of manuscripts through all assessment stages, passing diplomatic but often necessary reminders to assessors. At Psychological Medicine we have the benefit of the publishing facilities of an excellent academic publisher, Cambridge University Press, and our Technical Editor Penny McLaughlan handles the manuscripts after acceptance.

How has the work changed over the years? The volume has certainly undergone a major increase. In my case this is partly due to my own move to a larger journal, but much of it reflects more general trends: more research, more published papers, indeed more journals. The number of papers submitted to Psychological Medicine has increased by around $60 \%$ since 1994 , and with it the editorial workload, the pressure on space, and the competition in the priority for acceptance. Fortunately the development and increased power of PCs and software in the last twenty years has helped authors to revise more easily, and editors to keep track of their own actions.

Then there is the advent of the impact factor: a tyrant, but only if one permits it to be that. All editors know that impact factors are flawed. They vary markedly between different fields. They weight too highly journals, which are read and quoted rapidly since the impact factor is confined to the first two years after papers have been published. Another index, the cited half-life, a measure of the length of time for which papers go on being quoted, and hence their enduring value, is also published but receives less attention. The conventional impact factor also overweights certain kinds of papers, such as review articles, which are quoted widely and conveniently and do serve a useful purpose, but make a very limited contribution to new knowledge. All the indices reward self-citation. There have been many articles pointing out these flaws in impact factors (Amin \& Mabe, 2000; Bloch \& Walter, 2001; Adam 2002). Those who pay a lot of attention to them (including certain universities, funders, and promotions committees in a number of countries) should read the critiques.

The experience of encountering many manuscripts over a range of topics does help to generate a sense of perspective. A good research paper needs to tell a story, with a rationale, methods, results and conclusions which can be summarised in a take-home message. This last may sound journalistic, but it is important if the paper is to have influence. There is a delicate balance between on the one hand 'salami slicing' - too much fragmentation of a piece of research into many papers, and on the other hand putting too much in a single paper so that the message becomes confused and hard to assimilate. The research methods need to be good, the analysis sound, the discussion balanced and self critical where appropriate, and the conclusions justified.
A good paper also needs a good research question. Replication is always necessary, and most scientific advance is in small incremental steps rather than in giant leaps forward. Nevertheless, compared with some more rapidly advancing medical fields, too many psychiatric research manuscripts look like replications of the already well replicated, perhaps in a slightly different setting, or the tidying up of relatively minor issues. Such papers are worthy and have a place, but it is hard to prioritise them for already pressured and limited space. A journal cannot accept too many papers without badly lengthening its backlog and unduly delaying publication of many papers.

The story of journals is only now entering its most interesting phase. The printed word had existed for many centuries before the advent of scientific journals. Now, the development of the world wide web in the 1990s and the rapid growth of online access are changing old customs fast. No-one at present quite knows where it will end. Most major journals are now online, at least to subscribers and libraries. Papers in PDF format can reproduce accurately the printed original. We can now publish Psychological Medicine papers on our website as soon as they are in final form, before the printed version has appeared. Additional material such as further tables, appendices, full rating scales, can easily be accommodated in this form. Increasing numbers of journals, Psychological Medicine included, offer online subscriptions without the printed version, and offer non-subscribers abstracts with the possibility of downloading the full paper for payment.

A good journal tries to be a guarantor of quality, by peer review and Editorial Board judgement, and the manuscript assessment process needs to continue. Journals are unlikely to go away: rather, they are still proliferating. Other kinds of web-based information for the general public illustrate well the problems of unreliable misinformation which can appear when good quality review is lacking, and this problem in respect of health information has received considerable comment in medical journals in the last year.

Soon however, the online version of the peer-reviewed journal may become the primary version and the printed one more archival. This is a pivotal time in the evolution of journals, when a period of considerable growth in the volume of printed pages is being succeeded by a great growth in electronic access. Further changes in the next few years are likely.

\section{REFERENCES}

Adam D. (2002). The counting house. Nature 415, 726-729.

Amin M. \& Mabe M. (2000). Impact factors: use and abuse. Perspectives in Publishing 1,1-6.

Bloch S. \& Walter G. (2001). The impact factor: time for a change Australian and New Zealand Journal of Psychiatry 35, 563-568. 